\title{
Global Academic Journal of Dentistry and Oral Health
}

Available online at https://www.gajrc.com

DOI: $\underline{10.36348 / \text { gajdoh.2021.v03i03.004 }}$

\section{"Correction of Severe Maxillary Prognathism and Facial Profile in a Mutilated Dentition case by Fixed Orthodontic Mechanotherapy" - A Case Report}

Dr. Bhushan Jawale ${ }^{1}$, Dr. Lishoy Rodrigues ${ }^{2}$, Dr. Vijay Naik ${ }^{3}$, Dr. Sriniwas Basavreddy ${ }^{4}$, Dr. Anand Ambekar ${ }^{5}$, Dr: Shrinivas Ashtekar ${ }^{6}$

${ }^{1}$ Professor, Dept. of Orthodontics and Dentofacial Orthopedics, Sinhgad Dental College and Hospital, Vadgaon Bk, Pune, Maharashtra, India

${ }^{2}$ Post Graduate Resident, Dept. of Orthodontics and Dentofacial Orthopedics, Sinhgad Dental College and Hospital, Vadgaon Bk, Pune, Maharashtra, India

${ }^{3}$ Professor and HOD, Dept. of Orthodontics and Dentofacial Orthopedics, Maratha Mandal Dental College and Hospital, Belgaum, Karnataka, India

${ }^{4} \mathrm{HOD}$ and Professor, Dept. of Orthodontics and Dentofacial Orthopedics, SDM Dental College and Hospital, Dharwad, Karnataka, India

5Professor, Dept. of Orthodontics and Dentofacial Orthopedics, MIDSR Dental College and Hospital, Latur, Maharashtra, India ${ }_{6}^{6}$ Professor, Dept. of Orthodontics and Dentofacial Orthopedics, VPDC Dental College and Hospital, Sangli, Maharashtra, India

*Corresponding Author Abstract: A problem often confronting the orthodontist is that of missing molars. In

Dr. Lishoy Rodrigues evaluation of the individual case, the decision as to space closure or space regaining and eventual prosthetic reconstruction can be perplexing. Various diagnostic criteria,

Article History

Received: 19.04 .2021

Accepted: 31.05 .2021

Published: 06.06.2021 such as skeletal relation, arch-length analysis, inclination of teeth, and dental esthetics, must be evaluated. On the basis of this diagnostic information, a treatment alternative is chosen to correct the malocclusion. The solution may be found in maintaining space, necessitating post-orthodontic prosthetic replacement, or closing space and thus avoiding the need for artificial teeth. This case report evaluates the management of a 32 year old adult female patient having a mutilated malocclusion with multiple missing $1^{\text {st }}$ permanent molars. It was managed by routine orthodontic treatment which involved protraction of permanent $2^{\text {nd }}$ molars in the space available in the missing $1^{\text {st }}$ molar region. Cephalometric values revealed proclined and forwardly placed upper and lower front teeth, hence we sought the need to extract premolars as the nasolabial angle was acute and premolar extractions in this case would be needed for the convex facial profile correction. After the treatment, a marked improvement in patient's smile, facial profile and occlusion was achieved and there was a remarkable increase in the patient's confidence and quality of life. Correction of the mutilated malocclusion was achieved without tipping, rotation of the posterior teeth, or other problems. The profile changes and treatment results were demonstrated with proper case selection and good patient cooperation with fixed appliance therapy.

Keywords: Premolar extraction, Molar protraction, Replacement of missing $1^{\text {st }}$ molars, Adjunctive orthodontic treatment, Adult patient, Mutilated dentition, Fixed Orthodontic treatment, Missing $1^{\text {st }}$ permanent molars, Multiple missing molars.

Copyright (c) 2021 The Author(s): This is an open-access article distributed under the terms of the Creative Commons Attribution 4.0 International License (CC BY-NC 4.0) which permits unrestricted use, distribution, and reproduction in any medium for non-commercial use provided the original author and source are credited.

\section{INTRODUCTION}

When a $1^{\text {st }}$ permanent molar is lost, orthodontic replacement with $2^{\text {nd }}$ permanent molars would be an excellent treatment option if success were guaranteed. Stepovich [1] presented the possibilities of these methods without severe complications, such as root resorption and tipping of adjacent teeth. Roberts et al [2, 3] used endosseous implants placed in the posterior area to close missing molar spaces by mesial movement of the $2^{\text {nd }}$

Citation: Bhushan Jawale et al (2021). "Correction of Severe Maxillary Prognathism and Facial Profile in a Mutilated Dentition case by Fixed Orthodontic Mechanotherapy" - A Case Report. Glob Acad J Dent Oral Health; Vol-3, Iss- 3, pp- 43-48. 
molars. In recent years, orthodontic miniscrews, which are more convenient, simple, and cheaper than endosseous implants, have been used widely. Kyung et al [4] reported a 9-mm mesial movement of mandibular second molars, and Nagaraj et al [5] reported an 8-mm movement using miniscrews to close bilateral missing mandibular first molar spaces. Kravitz and Jolley [6] discussed problems, such as buccal proclination, during mandibular molar protraction with miniscrews. The management of missing molars requires an integrated multidisciplinary approach [7]. Generally the choice between space opening with tooth replacement and space closure with $2^{\text {nd }}$ molar substitution relies on several parameters to be considered before treatment planning. Commonly the choice is related to occlusal relationship (i.e., overjet and overbite, molar relationship), facial typology and profile, arch length, and tooth size discrepancies. The morphology of the $2^{\text {nd }}$ molar, in terms of size and shape, and its colour [8] also may address different treatment strategies. Finally, patient expectation and compliance can influence the treatment planning. In case of unilateral tooth agenesis, space opening is often recommended to improve the aesthetics of patients and preserve smile symmetry. On the contrary, in case of bilateral agenesis, space closure and space opening could be both performed with respect to the issues previously reported [9-12]. Space opening is advised in low-angle subjects, whilst in high-angle individuals space closure should be preferred to preserve arch anchorage and avoid clock-wise rotation of the lower jaw. Retruded profiles should be better treated with space opening and tooth substitution, in order to improve labial sagittal relationships. This treatment strategy should be avoided in subjects with bimaxillary dental protrusion [13-19], in which it could result in worsening of the profile. Molar relationship should be also considered. Molar class I or class III tendency should be better treated with space opening to preserve ideal occlusal anterior and posterior relationship (i.e., canine and molar relationship) and establish a solid angle class I. In case of full cusp or partial molar class II, space closure should be preferred to facilitate orthodontic biomechanics and reduce treatment duration. A stable molar class II and canine class I are then obtained. However, in case of arch length discrepancies extractions in the lower arch should be considered, thus obtaining a molar and canine class I. Anterior relationship, that is, overjet and overbite, must be taken into account in terms of facilitation of biomechanics. Reduced overjet and increased overbite may easily be improved by space opening mechanics, whilst increased overjet and reduced overbite may benefit from space closure. Shape and size of $2^{\text {nd }}$ permanent molars affect the possible rehabilitation choice. Our patient had grossly decayed maxillary left and mandibular right $1^{\text {st }}$ permanent molars which needed extractions. Hence we decided to go about with this case by extracting the grossly decayed molars and substituting the same by protraction the $2^{\text {nd }}$ permanent molars in the space available by extracting the $1^{\text {st }}$ permanent molars. Premolar extractions were also needed in this case as the patient presented with a severely prognathic and convex facial profile and severe upper and lower anterior proclination.

\section{CASE REPORT \\ Chief Complaint and Etiology}

An adult female patient, aged 32 years 6 months, sought an orthodontic evaluation with a chief complaint of 2 missing molar teeth and also wanted to get a replacement for the same. She also complained of forwardly placed upper and lower front teeth with inability to close her lips. The maxillary left and mandibular right $1^{\text {st }}$ permanent molars had been extracted due to severe caries.

\section{Extra-Oral Examination}

On Extra-oral examination, the patient had a convex facial profile, a posteriorly divergent face, grossly symmetrical face on both sides, incompetent lips, moderately deep mentolabial sulcus and an acute Nasolabial Angle with loss of upper lip support and everted lower lip, protruded upper and lower lip with loss of lip seal and increased lip strain, a Mesoprosopic facial form, Dolicocephalic head form, average width of nose and mouth, and posterior divergence of face. The patient had no relevant prenatal, natal, postnatal history, history of habits or a family history. On smiling, there was presence of severely proclined upper and lower anterior teeth with excessive show of upper front teeth and excessive show of upper gums.

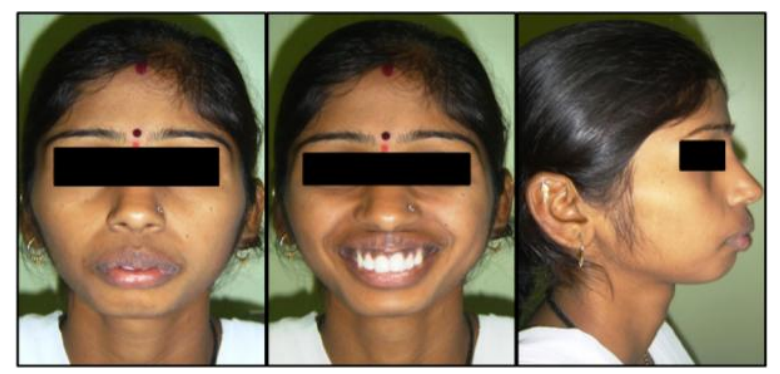

Fig-1: Pre-Treatment Extra-Oral Photographs

\section{Intra-Oral Examination}

Intraoral examination on frontal view shows presence of proclined upper and lower anterior teeth with an increased overjet and overbite and lower dental midline shifted to the left by $2.5 \mathrm{~mm}$. On lateral view the patient shows the presence of Class II Division 1 incisor relationship and a Class II canine relationship on both sides. 
Patient has proclined and forwardly placed upper and lower anterior teeth. On occlusal view, there is presence of $1^{\text {st }}$ molar extraction spaces seen in maxillary left and mandibular right posterior region. The upper and lower arch also show presence of a "U" shaped arch form.
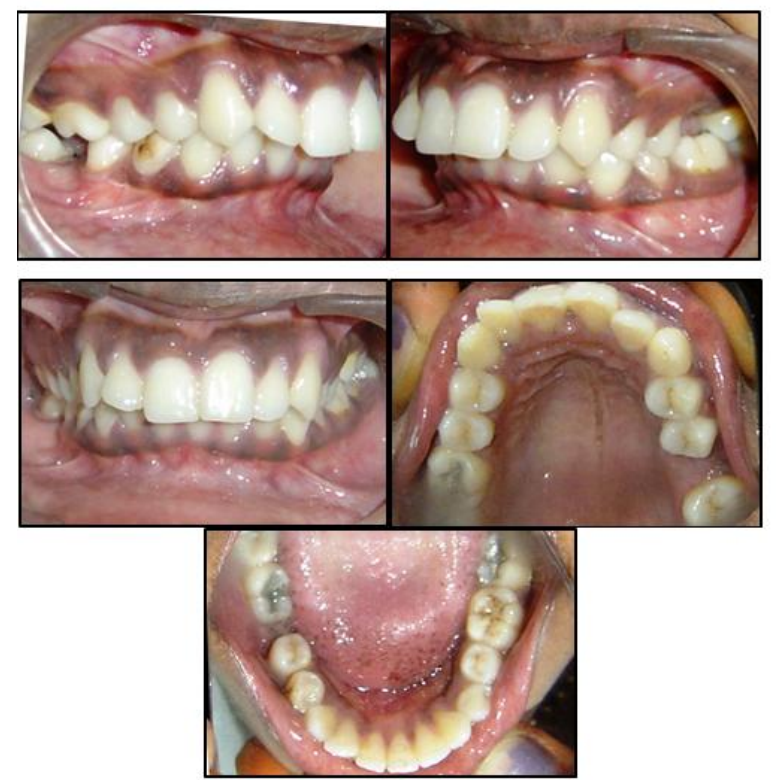

Fig-2: Pre-Treatment Intra-Oral Photographs

Table-1: Pre Treatment Cephalometric Readings

\begin{tabular}{|l|l|}
\hline PARAMETERS & PRE- TREATMENT \\
\hline SNA & $84^{\circ}$ \\
\hline SNB & $81^{\circ}$ \\
\hline ANB & $3^{\circ}$ \\
\hline WITS & $2 \mathrm{~mm}$ \\
\hline MAX. LENGTH & $95 \mathrm{~mm}$ \\
\hline MAN. LENGTH & $98 \mathrm{~mm}$ \\
\hline IMPA & $108^{\circ}$ \\
\hline NASOLABIAL ANGLE & $86^{\circ}$ \\
\hline U1 TO NA DEGREES & $36^{\circ}$ \\
\hline U1 TO NA mm & $5 \mathrm{~mm}$ \\
\hline L1 T0 NB DEGREES & $32^{\circ}$ \\
\hline L1 TO NB mm & $6 \mathrm{~mm}$ \\
\hline U1/L1 ANGLE & $108^{\circ}$ \\
\hline FMA & $28^{\circ}$ \\
\hline Y AXIS & $74^{\circ}$ \\
\hline
\end{tabular}

\section{Diagnosis}

This 32 year old female patient was diagnosed with a Class II malocclusion on a Class II Skeletal base, an average to vertical growth pattern, missing 26 and 46, increased overjet and overbite with a lower midline shift to the left by $2.5 \mathrm{~mm}$, proclined upper and lower anterior teeth, protruded upper and lower lips, a slightly retruded chin, moderately deep mentolabial sulcus, increased lip strain, incompetant lips with an acute Nasolabial angle, a convex facial profile with a posteriorly divergent face.

\section{List of Problems}

1. Missing 26 and 46.

2. Proclined upper and lower front teeth.

3. Non congruent dental midlines.

4. Increased overjet and overbite.

5. Incompetent lips.

6. Protruded upper and lower lips.

7. Increased lip strain.

8. Reduced Nasolabial angle.

9. Convex facial profile.

\section{Treatment Objectives}

1. Protraction of 27 and 47 into the extraction space site.

2. To correct the proclined upper and lower front teeth.

3. To correct the non-congruent dental midlines.

4. To achieve an ideal overjet and overbite.

5. To improve the lip competency.

6. To correct the protruded upper and lower lips.

7. To decrease the lip strain.

8. To achieve a Class I incisor, canine and molar relationship.

9. To achieve a pleasing smile and a pleasing profile.

\section{Treatment Plan}

- Fixed appliance therapy with Pre-adjused Edgewise bracket system with extraction of all $1^{\text {st }}$ premolars

- Initial leveling and alignment with 0.012", 0.014", 0.016", 0.018", 0.020" NiTi archwires following sequence A of MBT

- $\quad 2^{\text {nd }}$ molar protraction of 27 and 47 into the $1^{\text {st }}$ molar extraction site with the help of Elastomeric chains

- Retraction and closure of spaces by use of $0.019 "$ x 0.025 " rectangular NiTi followed by 0.019 " x 0.025 " rectangular stainless steel wires.

- Final finishing and detailing with 0.014 " round stainless steel wires

- Retention by means of Begg's Wrap-around retainers along with lingual bonded retainers in the upper and lower arch

\section{Treatment Alternatives}

Spaces caused by missing molars could be corrected by prosthetic bridges, dental implants, auto transplantation of $2^{\text {nd }}$ molars, or mesial orthodontic movement of $2^{\text {nd }}$ molars. Prosthetic bridges offered the advantage of short treatment time but must be accompanied by significant tooth preparation. Dental implants permit conservation of tooth structure but require surgery. Auto transplantation also required surgery, and successful transplantation could not be guaranteed. After explaining and counseling the patient about all the treatment options available, our patient finally chose replacement of the missing $1^{\text {st }}$ permanent 
molars with $2^{\text {nd }}$ molars by the process of orthodontic intervention.

\section{Treatment Progress}

Complete bonding \& banding in both maxillary and mandibular arch was done, using Preadjusted Edgewise bracket system. Extraction of 14, 24,34 and 44 was done. Initially a 0.012 " NiTi wire was used which was followed by 0.014, 0.016", 0.018 ", $0.020^{\prime \prime}$ Niti archwires following sequence A of MBT. After 6 months of alignment and leveling NiTi round wires were discontinued. Retraction and closure of spaces was then started by use of $0.019 " \mathrm{x}$ 0.025 " rectangular NiTi followed by 0.019 " x 0.025 " rectangular stainless steel wires. Reverse curve of spee in the lower arch and exaggerated curve of spee in the upper arch was incorporated in the heavy archwires to prevent the excessive bite deepening during retraction process and also to reduce the increased overbite. Routine orthodontic treatment involved protraction of permanent $2^{\text {nd }}$ molars in the space available in the missing $1^{\text {st }}$ molar region. Protraction of $2^{\text {nd }}$ permanent molars for closure of existing $1^{\text {st }}$ molar spaces was done with the help of Elastomeric chains delivering light continuous forces and replaced after every 4 weeks due to force decay and reduction in its activity. Extraction of all $1^{\text {st }}$ premolars was done to correct the severely proclined maxillary and mandibular anterior region. Finally light settling elastics were given with rectangular steel wires in lower arch and 0.012" light NiTi wire in upper arch for settling, finishing, detailing and proper intercuspation. The extraction spaces were completely closed down by protraction of $2^{\text {nd }}$ permanent molars and the profile of the patient improved significantly to more Orthognathic with a pleasant and consonant smile arc on smiling.

Table-2: Post Treatment Cephalometric Readings

\begin{tabular}{|l|l|}
\hline PARAMETERS & POST-TREATMENT \\
\hline SNA & $82^{\circ}$ \\
\hline SNB & $81^{\circ}$ \\
\hline ANB & $1^{\circ}$ \\
\hline WITS & $1 \mathrm{~mm}$ \\
\hline MAX. LENGTH & $92 \mathrm{~mm}$ \\
\hline MAN. LENGTH & $97 \mathrm{~mm}$ \\
\hline IMPA & $95^{\circ}$ \\
\hline NASOLABIAL ANGLE & $106^{\circ}$ \\
\hline U1 TO NA DEGREES & $26^{\circ}$ \\
\hline U1 TO NA mm & $2 \mathrm{~mm}$ \\
\hline L1 TO NB DEGREES & $24^{\circ}$ \\
\hline L1 TO NB mm & $1 \mathrm{~mm}$ \\
\hline U1/L1 ANGLE & $131^{\circ}$ \\
\hline FMA & $27^{\circ}$ \\
\hline Y AXIS & $72^{\circ}$ \\
\hline
\end{tabular}

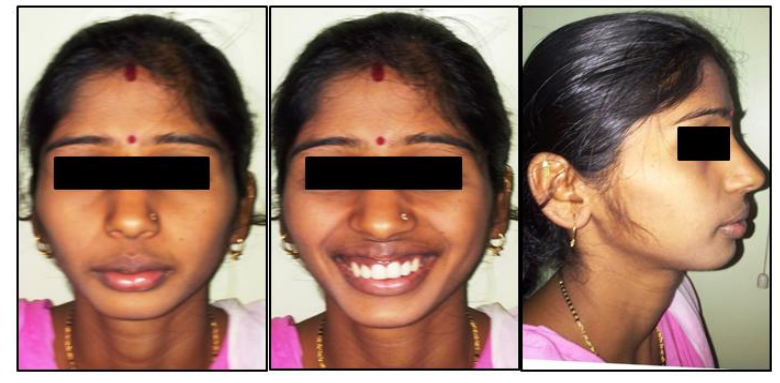

Fig-3:Post-Treatment Extra-Oral Photographs
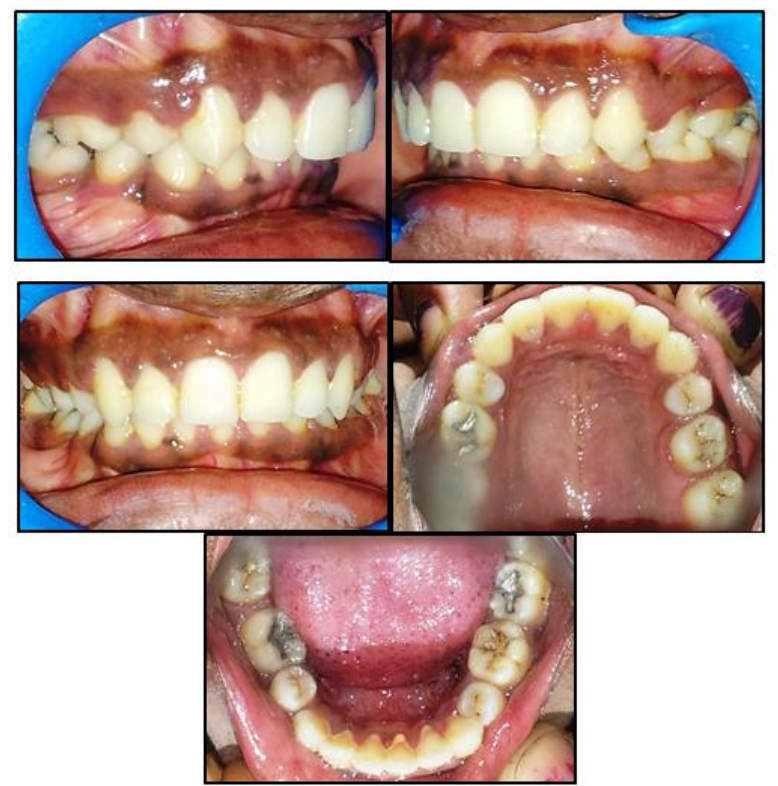

Fig-4: Post-Treatment Intra-Oral Photographs

\section{Treatment Results}

All of the original pre-treatment objectives were achieved. The maxillary and mandibular arches were well aligned and coordinated. Class I incisor and canine relationship was achieved bilaterally. A Class II Molar relationship was achieved on right side and Class I on the right side. Maxillary and mandibular anterior proclination was corrected by extraction of all $1^{\text {st }}$ premolars followed by retraction. The chief complain of missing molars and forwardly placed upper and lower front teeth was addressed. An ideal overjet and overbite was achieved and dental midlines were congruent at the end of the treatment. The decreased nasolabial angle at pre-treatment was improved, lips changed from being incompetent to competent and lip strain decreased significantly at the end of treatment with a good lip support, noneverted lower lip and reduced proclination of upper and lower lip. Wire fixed retainers were attached to the lingual aspect of each tooth from the right to the left canines in both arches. The patient wore a Begg's wrap around retainer for 15 hours per day for the first 2 months, followed by another 10 months of nighttime wear. 


\section{DISCUSSION}

Treatment of a mutilated dentition with missing molars is challenging. A well-chosen individualized treatment plan, undertaken with sound biomechanical principles and appropriate control of orthodontic mechanics to execute the plan is the surest way to achieve predictable results with minimal side effects. Class II malocclusion with bimaxillary dento-alveolar protrusion might have any number of a combination of the skeletal and dental component. Hence, identifying and understanding the etiology and expression of malocclusion and identifying differential diagnosis is helpful for its correction. The patient's chief complaint was missing molars and forwardly placed upper and lower front teeth. The selection of orthodontic fixed appliances is dependent upon several factors which can be categorized into patient factors, such as age and compliance, and clinical factors, such as preference/familiarity and laboratory facilities. After analyzing the case thoroughly and reading all pretreatment cephalometric parameters along with evaluating the patients profile clinically, a decision was made to replace the missing $1^{\text {st }}$ permanent molars with $2^{\text {nd }}$ permanent molars by protracting them into the available space and correction of maxillary and mandibular anterior proclination by extraction of all $1^{\text {st }}$ permanent premolars. Since the cephalometric values revealed severely proclined and forwardly placed upper and lower front teeth, we sought the need to extract all $1^{\text {st }}$ premolars as the nasolabial angle was already acute and premolar extractions in this case would improve the facial profile and would result in an aesthetic appearing facial profile. There was improvement in occlusion, smile arc, profile and Nasolabial angle at the end of the treatment. Successful results were obtained after the fixed MBT appliance therapy within a stipulated period of time. The overall treatment time was 18 months. After this active treatment phase, the profile of this 32 year old adult female patient improved significantly as seen in the post treatment Extra-oral photographs. Removable Begg's retainers were then delivered to the patient along with fixed lingual bonded retainers in upper and lower arch. Patient was very satisfied at the end of the treatment.

Table-3: Comparison of Pre and Post Treatment Cephalometric Readings

\begin{tabular}{|l|l|l|}
\hline PARAMETERS & PRE- TREATMENT & POST-TREATMENT \\
\hline SNA & $84^{\circ}$ & $82^{\circ}$ \\
\hline SNB & $81^{\circ}$ & $81^{\circ}$ \\
\hline ANB & $3^{\circ}$ & $1^{\circ}$ \\
\hline WITS & $2 \mathrm{~mm}$ & $1 \mathrm{~mm}$ \\
\hline MAX. LENGTH & $95 \mathrm{~mm}$ & $92 \mathrm{~mm}$ \\
\hline MAN. LENGTH & $98 \mathrm{~mm}$ & $97 \mathrm{~mm}$ \\
\hline IMPA & $108^{\circ}$ & $95^{\circ}$ \\
\hline NASOLABIAL ANGLE & $86^{\circ}$ & $106^{\circ}$ \\
\hline U1 TO NA DEGREES & $36^{\circ}$ & $26^{\circ}$ \\
\hline U1 TO NA mm & $5 \mathrm{~mm}^{\circ}$ & $2 \mathrm{~mm}^{\circ}$ \\
\hline L1 TO NB DEGREES & $32^{\circ}$ & $24^{\circ}$ \\
\hline L1 TO NB mm & $6 \mathrm{~mm}$ & $1 \mathrm{~mm}$ \\
\hline U1/L1 ANGLE & $108^{\circ}$ & $131^{\circ}$ \\
\hline FMA & $28^{\circ}$ & $27^{\circ}$ \\
\hline Y AXIS & $74^{\circ}$ & $72^{\circ}$ \\
\hline
\end{tabular}

\section{CONCLUSION}

The case report depicts and highlights the role of Orthodontics in adjunctively treating an adult female patient with multiple missing molars and proclined maxillary and mandibular incisors. The planned goals set in the pretreatment plan were successfully attained. The missing molars were replaced by protraction of $2^{\text {nd }}$ permanent molars into the available extraction spaces of $1^{\text {st }}$ permanent molars and the upper and lower anterior proclination was corrected with fixed orthodontic treatment by executing extraction of premolars. Good intercuspation of the teeth was maintained with class I incisor, canine and molar relationship. The maxillary and mandibular teeth were found to be esthetically satisfactory in the line of occlusion.
Patient had an improved smile and facial profile. The correction of the malocclusion was achieved, with a significant improvement in the patient aesthetics and self-esteem.

\section{REFERENCES}

1. Stepovich MI. (1979). A clinical study on closing edentulous spaces in the mandible. Angle Orthod, 49:227-33.

2. Roberts WE, Marshall KJ, Mozsary PG. (1990). Rigid endosseous implant utilized as anchorage to protract molars and close an atrophic extraction site. Angle Orthod, 60:135-52.

3. Roberts WE, Nelson CL, Goodacre CJ. (1994). Rigid implant anchorage to close a mandibular 
first molar extraction site. J Clin Orthod, 28:693704.

4. Kyung SH, Choi JH, Park YC. (2003). Miniscrew anchorage to protract lower second molars into first molar extraction sites. J Clin Orthod, 37:575-9.

5. Nagaraj K, Upadhyay M, Yadav S. (2008). Titanum screw anchorage for protraction of mandibular second molars into first molar extraction sites. Am J Orthod Dentofacial Orthop,134: 583-91.

6. Kravitz ND, Jolley T. 2(008). Mandibular molar protraction with temporary anchorage devices. J Clin Orthod, 42:351-5.

7. L. Savarrio and G. T. McIntyre. (2005). "To open or to close space-that is the missing lateral incisor question," Dental Update, vol. 32, no. 1, pp. 16-25. View at: Google Scholar

8. S. Wriedt, P. Werner, and H. Wehrbein. (2007). "Tooth shape and color as criteria for or against orthodontic space closure in case of a missing lateral incisor," Journal of Orofacial Orthopedics, vol. 68, no. 1, pp. 47-55. View at: Publisher Site | Google Scholar

9. M. Rosa and B. U. Zachrisson. (2010). "The space-closure alternative for missing maxillary lateral incisors: an update," Journal of Clinical Orthodontics, vol. 44, no. 9, pp. 540-561. View at: Google Scholar

10. G. Richardson and K. A. Russell. (2001). "Congenitally missing maxillary lateral incisors and orthodontic treatment considerations for the single-tooth implant," Journal of the Canadian Dental Association, vol. 67, no. 1, pp. 25-28. View at: Google Scholar

11. B. J. Millar and N. G. Taylor. (1995). "Lateral thinking: the management of missing upper lateral incisors," British Dental Journal, vol. 179, no. 3, pp. 99-106. View at: Google Scholar

12. E. Argyropoulos and G. Payne. (1988). "Techniques for improving orthodontic results in the treatment of missing maxillary lateral incisors A case report with literature review," American Journal of Orthodontics and Dentofacial Orthopedics, vol. 94, no. 2, pp. 150165. View at: Google Scholar

13. Bhushan Jawale et al. (2021). "Correction of Spaced Dentition with Fixed Orthodontic Preadjusted Edgewise Bracket System" - A Case Report. South Asian Res J Oral Dent Sci, 3(3), 4552.

14. Bhushan Jawale et al. (2021). "Adjunctive Orthodontic Treatment in an Adult Patient with Mutilated Dentition" - A Case Report On Multidisciplinary Orthodontics. Glob Acad J Dent Oral Health; Vol-3, Iss- 3, pp-36-41.

15. Bhushan Jawale et al. (2021). "Treatment of Severe Crowding and Bimaxillary Dental Protrusion in a Patient with Angle's Class I Malocclusion and a Vertical Growth Pattern"- A Case Report On Orthodontic Camouflage. Saudi J Oral Dent Res, 6(5): 203- 208.

16. Bhushan Jawale et al. (2021). "Conventional MBT Mechanotherapy for Management of Bimaxillary Dentoalveolar Protrusion" - A Case Report. EAS J Dent Oral Med, 3(3), 65-72.

17. Bhushan Jawale et al. (2021). Wonders of Rapid Maxillary Expansion and Lower Premolar Extractions in Correction of a Skeletal Class III Case with Maxllary Deficiency and Mandibular Excess\| - A Case Report on Non- Surgical Orthodontic Camouflage. Saudi J Oral Dent Res, 6(5): 192-202.

18. Bhushan Jawale et al. (2021). "Maxillary 1st Premolar Extractions For Correction of Proclined Upper Dentition" - A Case Report. Int J Recent Sci Res. 12(05), pp. 41740-41745.

19. Bhushan Jawale et al. (2021). "Management of Reverse Overjet and Overbite in an Adult Patient with Angle's Class III Malocclusion and a Horizontal Growth Pattern" - A Case Report On Non-Surgical Orthodontic Camouflage. EAS J Dent Oral Med, 3(3), 73-77. 